\title{
Tratamentos alternativos para conservação de sementes de mamona (Ricinus communis L.)
}

\author{
Roberto Fontes Araujo $^{1}$, João Batista Zonta ${ }^{2}$, Eduardo Fontes Araujo ${ }^{3}$, Cézar Augusto Mafia Leal ${ }^{4}$
}

\begin{abstract}
${ }^{1}$ Dr. Pesquisador EPAMIG/SUDESTE, Campus UFV - Vila Gianetti, casa 46 e 47, CEP 36570-000, Viçosa-MG, Brasil. ${ }^{2}$ Dr. Analista, Embrapa Cocais, Av. Santos Dumont, 18, Bloco 3 (Prédio do Incra), Anil, São Luís-MA, Brasil, CEP 65046-660. ${ }^{3}$ Dr. Professor Associado, Universidade Federal de Viçosa, Departamento de Fitotecnia, Campus UFV - Vila Gianetti, casa 46 e 47, CEP 36570-000, Viçosa/MG, Brasil. ${ }^{4}$ Eng. Agrônomo, Universidade Federal de Viçosa, Campus UFV - Vila Gianetti, casa 46 e 47, 36570-000, Viçosa/MG, Brasil.

Autor para correspondência: João Batista Zonta (joao.zonta@embrapa.br).

Data de chegada: 14/09/2017. Aceito para publicação em: 27/03/2018.
\end{abstract}

$10.1590 / 0100-5405 / 187494$

\section{RESUMO}

Araujo, R.F.; Zonta, J.B.; Araujo, E.F.; Leal, C.A.M. Tratamentos alternativos para conservação de sementes de mamona (Ricinus communis L.) Summa Phytopathologica, v.45, n.1, p.89-96, 2019.

Objetivou-se avaliar os efeitos de tratamentos alternativos e do ambiente de armazenamento nas qualidades fisiológica e sanitária de sementes de mamona. Os tratamentos foram: derosal, vitavax-thiram, benzoato de sódio, sorbato de potássio, trichodermil SP, alecrim, alho, canela, cravo-da-índia e testemunha. As sementes foram submetidas a armazenamento em ambiente de laboratório e câmara fria por 12 meses. Sementes de mamona tratadas quimicamente, com derosal e vitavaxthiram, apresentaram qualidade fisiológica e sanitária superiores àquelas tratadas com produtos alternativos e sem tratamento, aos 12 meses de armazenamento. Sementes de mamona armazenadas em ambiente de laboratório, por período superior a oito meses, devem ser tratadas com fungicidas químicos tradicionais. Se armazenadas em câmara fria, a manutenção de sua germinação e vigor acima de $80 \%$ independe do tratamento fungicida utilizado. Os tratamentos fungicidas alternativos mais promissores foram o trichodermil, o sorbato de potássio e o alho, com destaque para o primeiro produto.

Palavras-chave: sanidade, germinação, armazenamento, fungo, vigor.

\section{ABSTRACT}

Araujo, R.F.; Zonta, J.B.; Araujo, E.F.; Leal, C.A.M. Alternative treatments for the conservation of castor seeds (Ricinus communis L.). Summa Phytopathologica, v.45, n.1, p.89-96, 2019.

The aim of this study was to evaluate the effects of alternative treatments and storage environment on the physiological and sanitary qualities of castor seeds. Treatments were: derosal, vitavax-thiram, sodium benzoate, potassium sorbate, trichodermil SP, rosemary, garlic, cinnamon, Indian clove and control treatment. The seeds were subjected to storage in laboratory and in a cold chamber for 12 months. Castor seeds chemically treated with derosal and vitavax-thiram showed physiological and sanitary quality superior to those of seeds treated with alternative products and without treatment at 12 months of storage. Castor seeds stored in laboratory, for a period longer than 8 months, must be treated with traditional chemical fungicides. If the seeds are stored in a cold chamber, the maintenance of their germination and vigor above $80 \%$ does not depend on the used fungicide treatment. The most promising alternative fungicides were trichodermil, potassium sorbate and garlic, especially the first product.

Keywords: sanity, germination, storage, fungus, vigor

No Brasil, com o advento do biodiesel, a cultura da mamona (Ricinus communis L.) teve uma expansão da área plantada, resultando em um considerável aumento na produção. A utilização de sementes com qualidades fisiológica, sanitária e física superiores é de fundamental importância para o estabelecimento e desenvolvimento da cultura, garantia para o sucesso do empreendimento agrícola. Para a obtenção de lotes de sementes com alta qualidade, cuidados especiais devem ser tomados durante as fases de produção no campo e de póscolheita, visando minimizar danos ambientais e físicos que provoquem redução na germinação, no vigor e na sanidade das sementes. Quando bem conduzido, o armazenamento de sementes minimiza o processo deteriorativo e o descarte de lotes. Para sementes oleaginosas, a condução adequada desta etapa é ainda mais importante, porque são mais propensas à deterioração, devido à menor estabilidade química dos lipídios em relação ao amido $(4,6,15)$. As condições ambientais de armazenamento são os fatores mais importantes para a conservação da viabilidade das sementes, especificamente a temperatura e o teor de água. A temperatura contribui significativamente, afetando a velocidade dos processos bioquímicos e interferindo, indiretamente, no teor de água das sementes (2). Além desses fatores, o tratamento de sementes para o armazenamento ou o plantio pode ser visto como uma tecnologia que promove um seguro de baixo custo da cultura, garantindo o máximo rendimento e evitando a introdução de doenças. Para algumas culturas anuais de importância econômica, o tratamento de sementes é uma prática comum. No entanto, para a cultura da mamona, inexistem produtos químicos registrados para o tratamento de sementes.

Com base na recomendação para outras espécies oleaginosas alguns produtos químicos vêm sendo testados. Os ingredientes ativos carbendazim e carboxina+tiram apresentaram maior eficiência no controle de patógenos veiculados pelas sementes de mamona, mantendo a sua qualidade fisiológica $(18,20)$. Também, o tratamento de sementes de mamona com os fungicidas químicos vitavax-thiram+terraclor, 
vitavax-thiram, captan + derosal, derosal plus, captan e thiran propiciou satisfatório controle de fungos (11). Os fungicidas captan, tiabendazol e tiofanato-metílico reduziram a incidência de fungos, sendo eficientes para o tratamento de sementes de mamona, cultivar IAC-226 (10). A utilização de fungicidas naturais tem sido prática defendida por vários ambientalistas. Além dos benefícios proporcionados ao meio ambiente, tornam as sementes mais atrativas ao consumidor por não apresentarem efeito tóxico à saúde. Diversos estudos têm demonstrado o efeito inibidor desses fungicidas naturais na microbiota das sementes (8). O eugenol e o timol, extraídos respectivamente do cravo e do tomilho, causaram inibição completa no desenvolvimento de Aspergillus flavus e A. versicolor. Chalfoun et al. (8) avaliaram o efeito dos condimentos alho, canela, cravo e tomilho sobre o desenvolvimento micelial dos fungos Rhizopus sp., Penicillium spp., Eurotium repens e Aspergillus niger, e constataram inibição total do óleo de canela sobre os fungos testados; os óleos de tomilho e alho tiveram o mesmo efeito nas concentrações mais altas, o cravo inibiu o desenvolvimento dos fungos a partir da concentração de $600 \mathrm{mg} / \mathrm{ml}$, exceto o fungo Penicillium spp., o que foi verificado na concentração de $800 \mathrm{mg} / \mathrm{ml}$. Ribeiro et al. (19) verificaram que o uso de produtos alternativos no controle da proliferação de fungos em sementes de café é uma alternativa ao uso de agentes químicos; as maiores reduções da população de fungos (Penicillium sp., Aspergillus sp. e Fusarium sp.) foram obtidas quando as sementes receberam o tratamento com alecrim, alho, cravo, sorbato de potássio, trichodermil, Tricho Plus e Mancozeb. Objetivou-se avaliar os efeitos de tratamentos alternativos e do ambiente de armazenamento nas qualidades fisiológica e sanitária de sementes de mamona.

\section{MATERIAL E MÉTODOS}

O experimento foi conduzido no Laboratório de Sementes da Empresa de Pesquisa Agropecuária de Minas Gerais (EPAMIG SUDESTE), e no Laboratório de Sementes do Departamento de Fitotecnia da Universidade Federal de Viçosa. As sementes foram tratadas com os seguintes produtos: Derosal (carbendazim), na dose $350 \mathrm{~mL} / 100 \mathrm{~kg}$ de sementes; Vitavax-Thiram (carboxina + tiram), na dose $400 \mathrm{~mL} / 100 \mathrm{~kg}$ de sementes; imersão das sementes durante um minuto em solução de benzoato de sódio (300 $\left.\mathrm{g} \mathrm{L}^{-1}\right)$; imersão das sementes durante um minuto em solução de sorbato de potássio (300 g $\mathrm{L}^{-1}$ ); Trichodermil SP, na dose $1 \mathrm{~g} / \mathrm{Kg}$ de sementes; alecrim (Rosmarinus officinalis); alho (Allium sativum); canela (Cinnamomum spp.); cravoda-índia (Caryophillus aromaticus), testados na concentração $100 \mathrm{~g}$ do extrato em pó/Kg de sementes e testemunha (sem tratamento). Após tratadas, amostras de $1 \mathrm{Kg}$ de sementes foram acondicionadas em sacos de algodão e armazenadas em ambiente de laboratório, sem controle de temperatura (entre 15 e $28^{\circ} \mathrm{C}$ ) e umidade relativa (entre 65 e $80 \%$ ), e em câmara fria, com temperatura de $14-16{ }^{\circ} \mathrm{C}$ e umidade relativa de $60-65 \%$. No início (tempo zero) e aos quatro, oito e doze meses de armazenamento, foram avaliados a germinação e o vigor das sementes. No início e após doze meses de armazenamento foi avaliada a sanidade das sementes. $\mathrm{O}$ teste de germinação foi conduzido de acordo com metodologia proposta por Brasil (5); O teste de envelhecimento acelerado foi conduzido de acordo com metodologia proposta por Marcos Filho (14); O teste de emergência em areia foi conduzido em casa de vegetação, com areia lavada e esterilizada em estufa a $200{ }^{\circ} \mathrm{C}$, durante duas horas. As sementes foram semeadas em bandejas plásticas a 3,0 cm de profundidade. A contagem foi realizada diariamente, no mesmo horário, a partir da primeira plântula emergida, até não se observar mais emergência; $O$ índice de velocidade de emergência (IVE) foi realizado juntamente com o teste de emergência. Para o cálculo foi utilizada fórmula proposta por Maguire (13); O teste de sanidade foi realizado por meio do método de incubação em papel de filtro sem congelamento (16). Foram utilizadas quatro repetições de 50 sementes para cada tratamento, as quais foram incubadas em placas de Petri (10 sementes por placa) contendo três folhas de papel de filtro, umedecidas em água destilada. As placas contendo as sementes foram incubadas por 10 dias à temperatura de $20 \pm 2{ }^{\circ} \mathrm{C}$, em câmara com fotoperíodo de 12 horas de luz branca fluorescente e 12 horas de escuro. A identificação dos fungos presentes nas sementes foi realizada com auxílio de microscópios estereoscópico e ótico, e de literatura (1).

O delineamento experimental utilizado foi o inteiramente casualizado, com oito repetições. Os tratamentos foram arranjados em esquema fatorial $10 \times 2 \times 4$ (dez tratamentos de sementes, dois ambientes e quatro períodos de armazenamento), à exceção do teste de sanidade, no qual o fatorial utilizado foi $10 \times 2 \times 2$ (dez tratamentos de sementes, dois ambientes e dois períodos de armazenamento), com quatro repetições. Os dados obtidos foram submetidos à análise de variância pelo teste F. Para analisar a qualidade físiológica das sementes durante o armazenamento, foi realizada análise de regressão polinomial. Para avaliar o efeito dos tratamentos de sementes e do ambiente de armazenamento, as médias, dentro de cada período de armazenamento, foram comparadas pelo teste de Skott-Knott. Para analisar a qualidade sanitária das sementes foram realizados análise de variância e teste de Skott-Knott. As análises de variância foram realizadas com auxílio do programa estatístico SISVAR.

\section{RESULTADOS E DISCUSSÃO}

Não houve efeito da interação tratamento de sementes vs. ambiente de armazenamento, dentro de cada período de armazenamento, na germinação e vigor de sementes de mamona. Portanto, os efeitos desses fatores foram analisados de forma individual. Os valores de germinação e vigor evidenciam a excelente qualidade inicial do lote de sementes, sem efeito imediato dos produtos. Em relação ao vigor, houve efeito de alguns tratamentos, variáveis entre os diferentes testes; porém, os valores foram muito próximos e altos, podendo ser considerados praticamente semelhantes, ou seja, sem efeito (Tabelas 1 e 2).

Observou-se efeito do ambiente de armazenamento na qualidade fisiológica das sementes. A câmara fria foi mais eficiente que o ambiente de laboratório na conservação das sementes; a germinação e o vigor, pelo teste de envelhecimento acelerado (Tabela 1), aos oito e doze meses de armazenamento, foram superiores para as sementes armazenadas em temperaturas mais baixas, na câmara fria.

Para os testes de emergência em areia e IVE (Tabela 2), a eficiência da câmara fria ocorreu já aos quatro meses, evidenciando que esses testes foram mais sensíveis que o teste de envelhecimento acelerado. Assim, verifica-se que as sementes de mamona, independente do tratamento utilizado, devem ser mantidas, preferencialmente, em ambiente refrigerado, principalmente quando se deseja manter a qualidade fisiológica das sementes por períodos superiores a quatro meses. Resultados semelhantes foram observados por Zonta et al. (22) com sementes de pinhão-manso (espécie oleaginosa), que concluíram que o armazenamento dessas sementes por período superior a 270 dias deve ser realizado em ambiente controlado.

O melhor desempenho germinativo de sementes armazenadas em baixas temperaturas pode ser atribuído ao efeito no seu metabolismo 
Tabela 1 - Germinação e vigor de sementes de mamona submetidas a tratamentos e armazenadas em dois ambientes (laboratório e câmara fria).

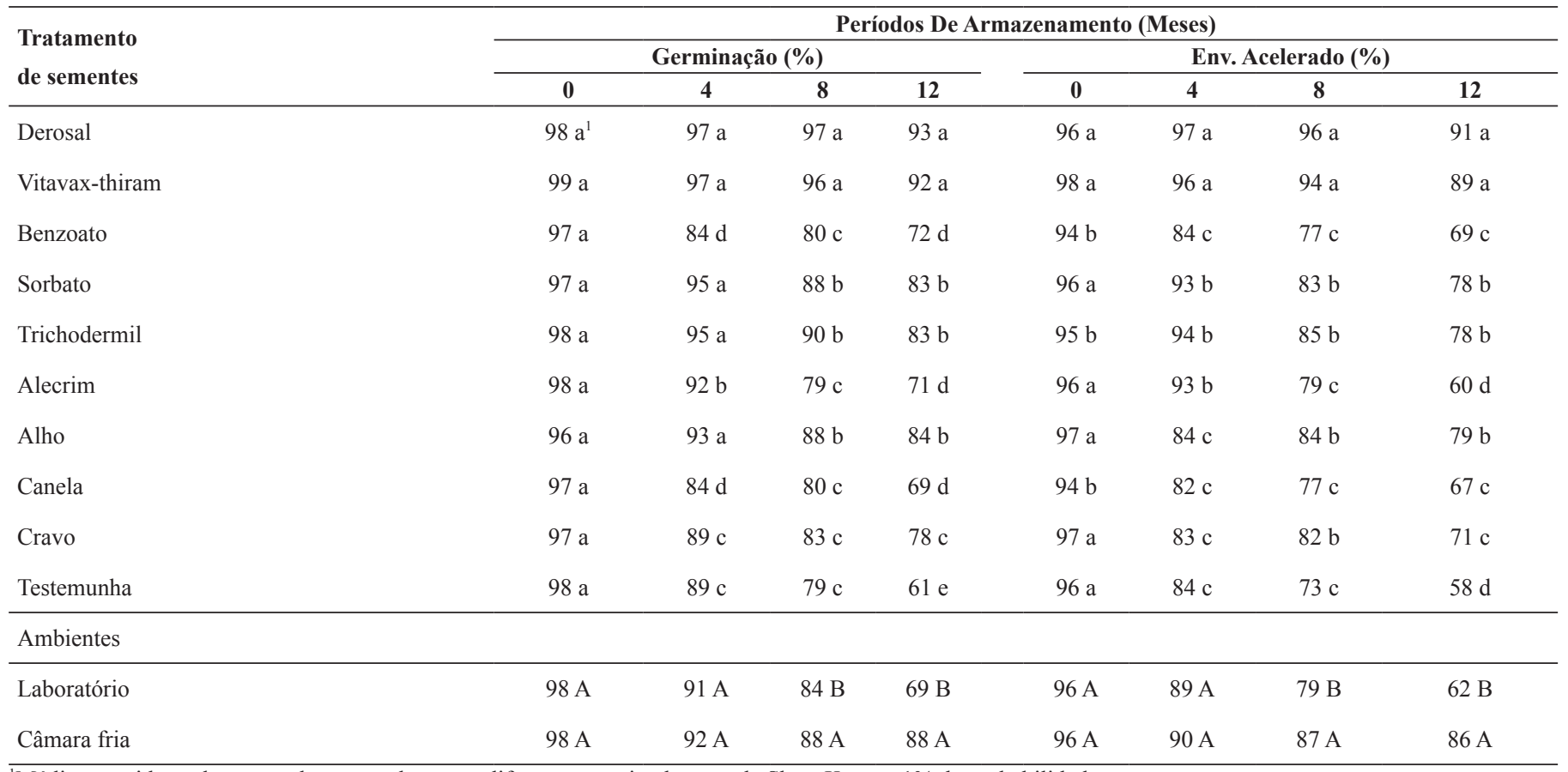

${ }^{1}$ Médias seguidas pela mesma letra na coluna não diferem entre si pelo teste de Skott-Knott a 1\% de probabilidade.

Tabela 2 - Vigor de sementes de mamona submetidas a tratamentos e armazenadas em dois ambientes (laboratório e câmara fria).

\begin{tabular}{|c|c|c|c|c|c|c|c|c|}
\hline \multirow{2}{*}{$\begin{array}{l}\text { Tratamento } \\
\text { de sementes }\end{array}$} & \multicolumn{8}{|c|}{ Períodos de armazenamento (meses) } \\
\hline & \multicolumn{4}{|c|}{ Emergência (\%) } & \multicolumn{4}{|c|}{ IVE } \\
\hline Derosal & $99 \mathrm{a}^{1}$ & $98 \mathrm{a}$ & $99 \mathrm{a}$ & $88 \mathrm{a}$ & $8,89 \mathrm{a}$ & $8,92 \mathrm{a}$ & $9,05 \mathrm{a}$ & $8,06 \mathrm{a}$ \\
\hline Vitavax-thiram & $98 \mathrm{a}$ & $97 \mathrm{a}$ & $97 \mathrm{a}$ & $88 \mathrm{a}$ & $8,82 \mathrm{a}$ & $8,85 \mathrm{a}$ & $8,76 \mathrm{~b}$ & $7,99 \mathrm{a}$ \\
\hline Benzoato & $97 \mathrm{a}$ & $83 \mathrm{c}$ & $78 \mathrm{c}$ & $62 \mathrm{~d}$ & $8,86 \mathrm{a}$ & $7,43 \mathrm{e}$ & $6,76 \mathrm{e}$ & $5,4 \mathrm{e}$ \\
\hline Trichodermil & $94 \mathrm{~b}$ & $94 \mathrm{a}$ & $88 \mathrm{~b}$ & $75 \mathrm{~b}$ & $8,68 \mathrm{~b}$ & $8,69 \mathrm{~b}$ & $7,80 \mathrm{c}$ & $6,66 \mathrm{~b}$ \\
\hline Alecrim & $97 \mathrm{a}$ & $89 \mathrm{~b}$ & $77 \mathrm{c}$ & $54 \mathrm{e}$ & $8,85 \mathrm{a}$ & $8,03 \mathrm{~d}$ & $6,68 \mathrm{e}$ & $4,60 \mathrm{f}$ \\
\hline Alho & $96 \mathrm{~b}$ & $90 \mathrm{~b}$ & $84 \mathrm{~b}$ & $68 \mathrm{c}$ & $8,76 \mathrm{~b}$ & $8,20 \mathrm{c}$ & $7,42 \mathrm{~d}$ & $5,98 \mathrm{~d}$ \\
\hline Canela & $97 \mathrm{a}$ & $83 \mathrm{c}$ & $77 \mathrm{c}$ & $56 \mathrm{e}$ & $8,80 \mathrm{a}$ & $7,38 \mathrm{e}$ & $6,72 \mathrm{e}$ & $4,65 \mathrm{f}$ \\
\hline \multicolumn{9}{|l|}{ Ambientes } \\
\hline Laboratório & $96 \mathrm{~A}$ & $88 \mathrm{~B}$ & $81 \mathrm{~B}$ & $57 \mathrm{~B}$ & $8,79 \mathrm{~A}$ & 7,91 B & $7,08 \mathrm{~B}$ & $4,89 \mathrm{~B}$ \\
\hline Câmara fria & $96 \mathrm{~A}$ & $92 \mathrm{~A}$ & $88 \mathrm{~A}$ & $80 \mathrm{~A}$ & $8,79 \mathrm{~A}$ & $8,33 \mathrm{~A}$ & $7,87 \mathrm{~A}$ & $7,11 \mathrm{~A}$ \\
\hline
\end{tabular}

${ }^{1}$ Médias seguidas pela mesma letra na coluna não diferem entre si pelo teste de Skott-Knott a 1\% de probabilidade.

celular, com reduções das reações químicas, das atividades enzimáticas e da respiração, favorecendo a conservação da sua qualidade fisiológica. Segundo Marcos Filho (15), ambientes com umidade relativa e temperatura baixas é mais adequado para conservação de sementes ortodoxas, como é o caso da mamona. Dentre as principais alterações envolvidas na deterioração de semente, destacam-se o esgotamento das reservas, a alteração da composição química, como a oxidação de lipídios e a quebra parcial das proteínas, a alteração das membranas celulares, com redução da integridade e aumento da permeabilidade e desorganização, e alterações enzimáticas e de nucleotídeos (21).

Analisando os tratamentos com produtos químicos e alternativos, dentro dos períodos de armazenamento estudados, verifica-se que o derosal e o vitavax-thiram apresentaram efeito positivo e superior aos demais produtos na germinação e no vigor das sementes, aos oito e 12 meses (Tabela 1). Os resultados corroboram com aqueles obtidos por Marroni et al. (17) e Tropaldi et al. (20), que verificaram 
efeito positivo do vitavax-thiram na porcentagem de germinação de sementes de mamona. Dos produtos alternativos testados, aos quatro meses de armazenamento, o sorbato, o trichodermil, o alecrim e o alho proporcionaram às sementes germinação acima de $90 \%$ e superior àquela das sementes não tratadas (testemunha). Aos oito meses, os tratamentos com sorbato, trichodermil e alho se sobressaíram aos demais tratamentos alternativos. Comportamento semelhante ao do teste de germinação foi observado para o teste de envelhecimento acelerado, com os tratamentos trichodermil, sorbato de potássio e alho tendo efeito positivo em relação aos demais tratamentos alternativos, sendo superiores à testemunha. No teste de emergência em areia, o tratamento trichodermil apresentou média superior aos demais tratamentos alternativos e à testemunha aos doze meses de armazenamento, para os parâmetros velocidade e porcentagem de emergência.

Durante o armazenamento, em ambiente de laboratório, houve decréscimo linear na germinação das sementes de todos os tratamentos, sendo que aquelas tratadas com derosal e vitavax-thiram apresentaram queda menos acentuada que os demais, e com a testemunha apresentando queda mais acentuada. Os tratamentos alternativos foram mais eficientes que a testemunha, com destaque para o trichodermil e o sorbato de potássio, com redução menos acentuada que os demais tratamentos alternativos (Figura 1A). Em câmara fria, durante o armazenamento, os tratamentos derosal, vitavax-thiram, sorbato, trichodermil e alho foram eficientes na conservação das sementes, apresentando queda menos acentuada que os demais tratamentos alternativos (Figura 1B).

Pelo teste de envelhecimento acelerado, observa-se decréscimo linear, durante o armazenamento em ambiente de laboratório, para todos os tratamentos, com os tratamentos derosal e vitavax-thiram apresentando menor decréscimo. Os tratamentos alternativos apresentaram decréscimo mais acentuado que os tratamentos químicos tradicionais, porém, menos acentuado que a testemunha, com destaque para o trichodermil e o sorbato de potássio (Figura 1C). Para as sementes armazenadas em câmara fria, não houve decréscimo com os tratamentos derosal e vitavax-thiram; os demais tratamentos apresentaram decréscimos de forma linear ou quadrática, com ressalvas para o trichodermil, que apresentou decréscimo menos acentuado que os demais (Figura 1D).

Para emergência em areia, durante o armazenamento em laboratório, todos os tratamentos apresentaram decréscimo linear (Figura 2A). Para as sementes armazenadas em câmara fria, não houve decréscimo na emergência quando tratadas com derosal e vitavax-thiram. Comparando entre os tratamentos alternativos, destaque para o trichodermil e o sorbato de potássio que apresentaram decréscimo menos acentuado que os demais (Figura 2B). Pelo IVE, no ambiente de laboratório, houve efeito prejudicial de todos os tratamentos (Figura 2C). Para as sementes armazenadas em câmara fria, houve efeito prejudicial nas sementes de todos os tratamentos, sendo que aquelas tratadas com derosal e vitavaxthiram apresentaram decréscimos no IVE bem menos acentuados que as dos demais. Entre os tratamentos alternativos, o trichodermil preservou melhor o vigor das sementes (Figura 2D).

Para o teste de sanidade, não houve efeito da interação tripla tratamento de sementes $\mathrm{x}$ ambiente de armazenamento $\mathrm{x}$ períodos de armazenamento (zero e doze meses). Somente a interação tratamento de sementes $\mathrm{x}$ período de armazenamento foi significativa. Os resultados mostram que as sementes submetidas aos tratamentos químicos com derosal e vitavax-thiram praticamente não se apresentavam com fungos (Tabela 3). Esses tratamentos químicos reduziram significativamente a incidência dos fungos de armazenamento (Aspergillus spp. e Penicilium spp.) nas sementes, principalmente, em relação à testemunha, influenciando positivamente na percentagem de plântulas normais, com ganhos na qualidade fisiológica mais evidenciados aos 12 meses de armazenamento. Corroborando com esses resultados, Bezerra et al. (3) concluíram que os tratamentos químicos proporcionaram redução na incidência de fungos do gênero Aspergillus, principalmente quando se utilizou o ingrediente ativo captan; também, Tropaldi et al. (20) concluíram que produtos a base dos ingredientes ativos derosal e vitavax-thiram são eficientes no controle de fungos patogênicos em sementes de mamona. O modo de ação desses fungicidas parece atuar de maneira bastante eficiente no controle da transmissão de fungos para as plântulas. Provavelmente, a maior incidência destes fungos nas sementes não tratadas quimicamente provocou redução na germinação. O controle desses patógenos é importante, uma vez que é comum sua invasão nas sementes após a colheita e todo esse evento pode resultar em redução de germinação e emergência de plântulas no campo. Em sementes de mamona é comum a alta incidência de fungos, principalmente quando colhidas com alto teor de água (12). O trichodermil controlou com bastante eficiência os fungos de armazenamento, o que justifica os resultados superiores de germinação e vigor das sementes tratadas com este produto, principalmente, em relação àquelas não tratadas (testemunha). Num segundo plano, aparecem o sorbato, e depois, o alho, que foram mais eficientes no controle desses patógenos que os demais tratamentos alternativos e a testemunha, os quais tiveram em suas sementes incidência maior desses fungos; em sementes de mamona armazenadas sem tratamentos, geralmente ocorre uma maior incidência de Aspergillus spp. e Penicillium spp., concordando com estudos de Coutinho et al. (9).

Com relação ao controle dos fungos de campo (Fusarium spp. e Cladosporium spp.) observou-se o mesmo padrão do controle dos fungos de armazenamento, com os tratamentos químicos com fungicida derosal e vitavax-thiram apresentando resultados mais eficientes que os demais produtos e a testemunha (Tabela 3). Apesar da grande eficiência dos fungicidas químicos tradicionais no controle de Fusarium spp. e do Cladosporium spp., e em segundo plano, do sorbato, do trichodermil e do alho, verifica-se uma redução natural da incidência desses fungos de campo, após 12 meses de armazenamento das sementes, diferentemente, dos fungos de armazenamento, que aumentaram. Esses resultados, que revelam comportamento diferente dos fungos de armazenamento e de campo nas sementes de mamona armazenadas são semelhantes aos obtidos por Kobori (11). Para ilustrar melhor, basta verificar, antes do armazenamento e aos 12 meses, a incidência desses dois tipos de fungo nas sementes não tratadas de mamona (testemunha); os fungos de armazenamento (Aspergillus spp e Penicilium spp) tiveram sua incidência nas sementes aumentada de 8 a 14\%, para 24 a 34\%, enquanto os fungos de campo (Fusarium spp. e Cladosporium spp.) tiveram a incidência de 38 e $46 \%$, para 11 e 19\%, antes e aos 12 meses de armazenamento, respectivamente.

Assim como os resultados deste trabalho, Kobori (11) verificou que o tratamento das sementes de mamona com fungicidas propicia bom controle de fungos durante o armazenamento, com destaque para os produtos químicos vitavax-thiram, vitavax-thiram + terraclor, captan + derosal, derosal plus, captan e thiram. No trabalho em questão, em geral, apesar da incidência de fungos nos tratamentos alternativos ter sido bem superior que nos tratamentos químicos tradicionais, tanto no início do armazenamento, quanto aos 12 meses, também é possível observar, em alguns produtos, considerável ação redutora na incidência destes nas sementes, evidenciando o potencial uso desses produtos alternativos, principalmente, o trichodermil, no controle desses patógenos. 

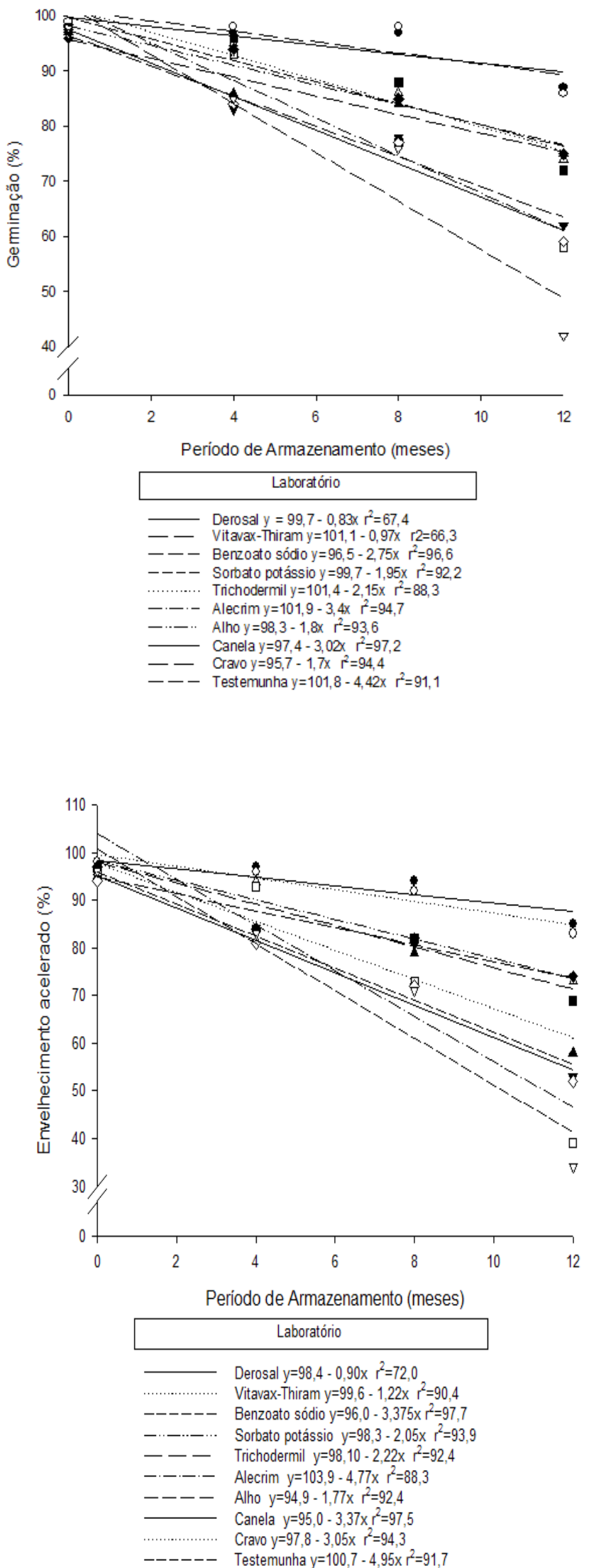
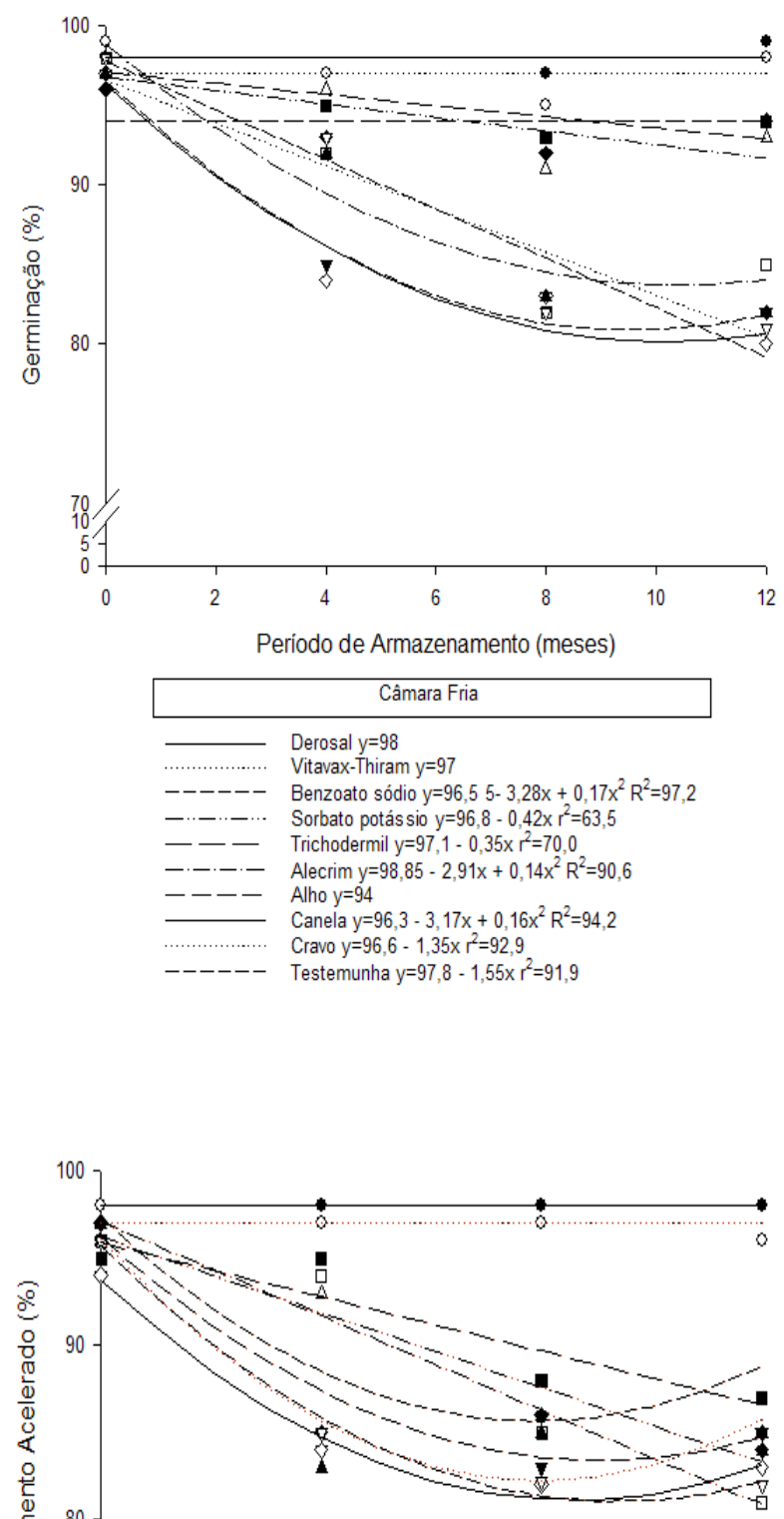

这

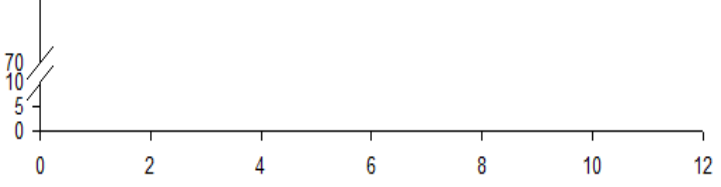

Periodo de Armazenamento (meses)

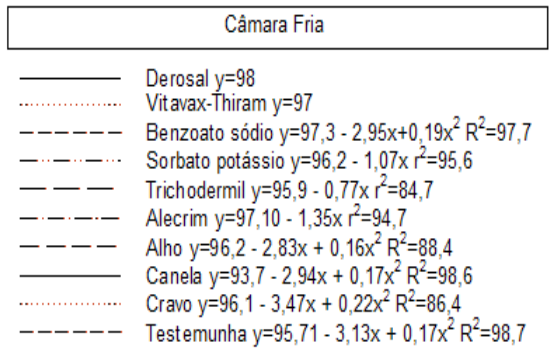

Figura 1. Germinação (A e B) e Envelhecimento Acelerado (C e D) de sementes de mamona submetidas a diferentes tratamentos e armazenadas em dois ambientes (laboratório e câmara fria). 

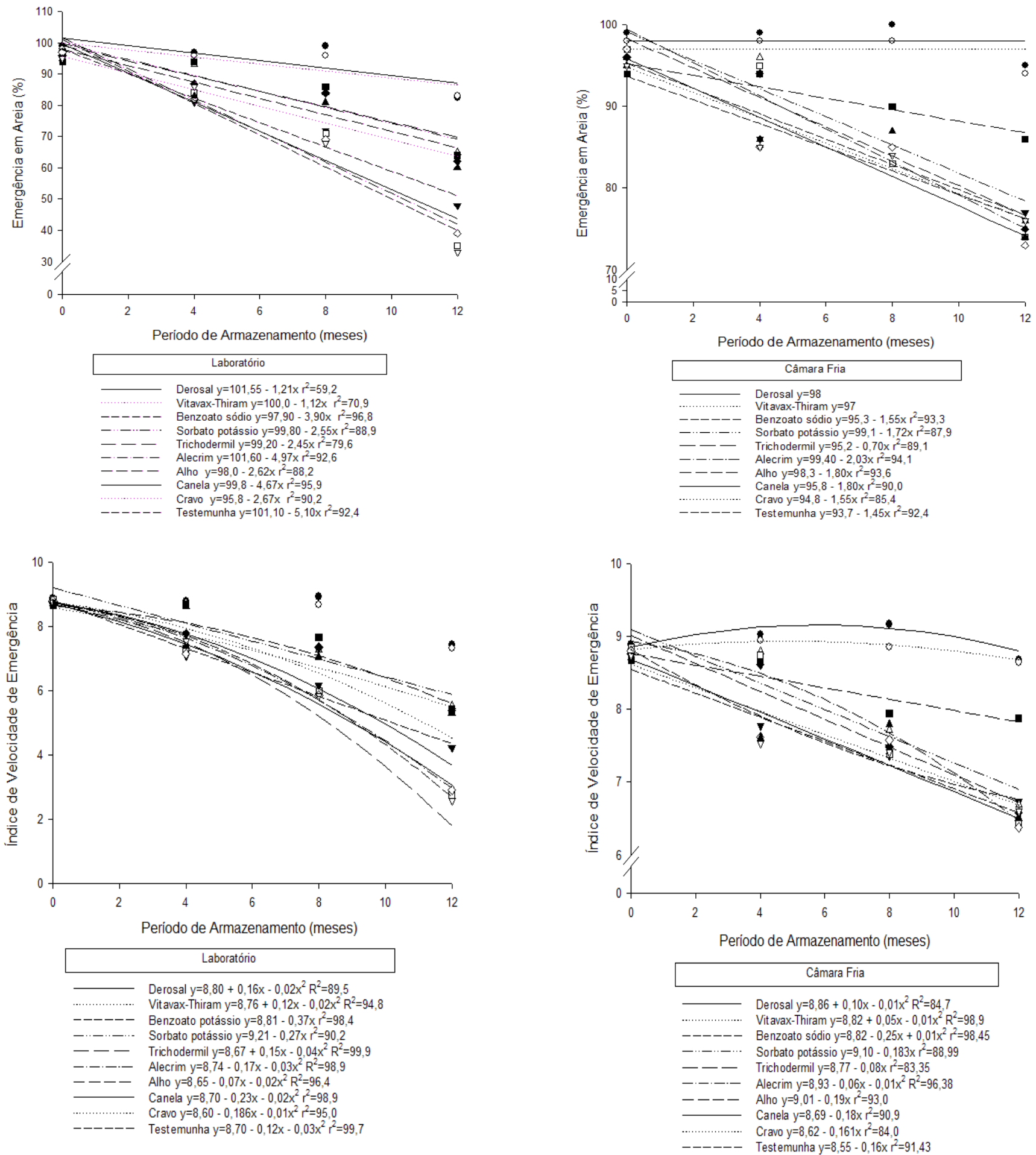

Figura 2. Emergência em Areia (A e B) e Índice de Velocidade de Emergência (C e D) de sementes de mamona submetidas a diferentes tratamentos e armazenadas em dois ambientes (laboratório e câmara fria).

Diversos autores relatam que o tratamento alternativo de sementes é uma opção viável para o controle de patógenos. Ribeiro et al. (19) verificaram que o uso de produtos alternativos no controle da proliferação de microrganismos é uma alternativa para o uso de produtos químicos em sementes de café; verificaram que as maiores reduções da população de fungos (Penicillium sp., Aspergillus sp. e Fusarium sp.) foram obtidas quando as sementes receberam o tratamento com alecrim, alho, cravo, sorbato de potássio, trichodermil, trichoplus e mancozeb. Chalfoun et al. (7) verificaram efeito inibidor do óleo de canela, de alho e de cravo sobre o desenvolvimento de Rhizopus sp., Pinicillium spp., Eurotium repens e Aspergillus niger. O grande problema, visivelmente observável nos tratamentos alternativos com extratos vegetais é a tecnologia de aplicação. Enquanto nos tratamentos químicos, praticamente todas as sementes, com a dosagem mínima recomendada, se apresentavam com a coloração característica do produto aplicado, as sementes submetidas aos tratamentos alternativos 
Tabela 3 - Incidência de fungos (\%) em sementes de mamona submetidas a diferentes tratamentos e armazenadas em dois ambientes (laboratório e câmara fria).

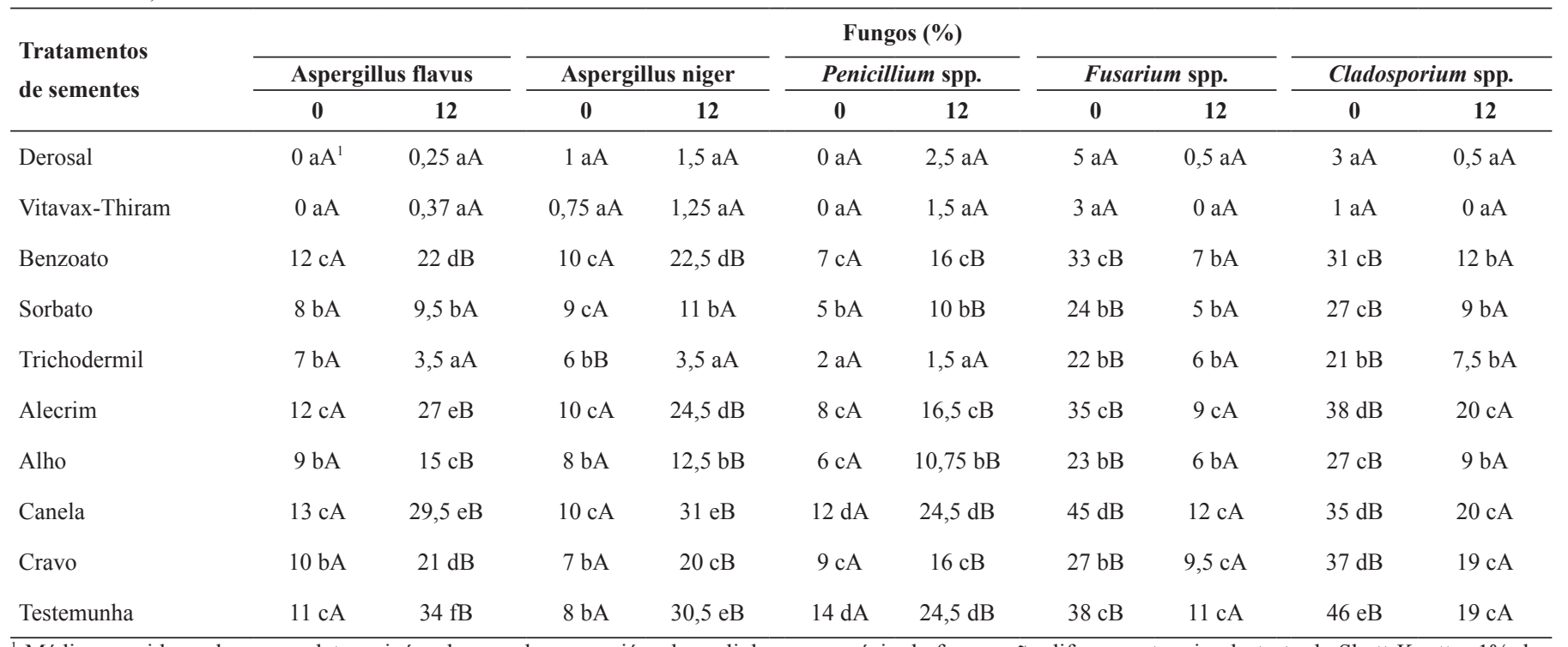

${ }^{1}$ Médias seguidas pela mesma letra minúscula na coluna e maiúscula na linha, por espécie de fungo, não diferem entre si pelo teste de Skott-Knott a 1\% de probabilidade.

não permaneciam com o produto aderido a elas. Principalmente, no caso dos extratos vegetais, que foram aplicados na forma de pó, verificou-se, durante o armazenamento, que quantidade considerável de extrato permanecia no fundo da embalagem; o contato maior do pó era com parte da amostra de sementes, atuando mais na atmosfera existente dentro da embalagem. Portanto, em um próximo estudo, seria interessante verificar se, em contato constante com as sementes, a aplicação desses produtos alternativos resultaria em melhor eficiência. Dessa forma, novos estudos devem ser realizados para se testar diferentes formas de aplicação, doses dos produtos alternativos e tipos de adesivo que garantam maior aderência dos mesmos às sementes.

As sementes de mamona quando tratadas quimicamente, com derosal e vitavax-thiram, apresentaram qualidade fisiológica e sanitária superiores àquelas tratadas com produtos alternativos e sem tratamento, aos 12 meses de armazenamento.

As sementes de mamona armazenadas em ambiente de laboratório, por período superior a oito meses, devem ser tratadas com fungicidas químicos tradicionais visando sua conservação e qualidade.

No caso das sementes serem armazenadas em câmara fria, a manutenção de sua germinação e vigor acima de $80 \%$ independe do tratamento fungicida utilizado. Os tratamentos fungicidas alternativos mais promissores foram o trichodermil, o sorbato de potássio e o alho, com destaque para o primeiro produto.

\section{AGRADECIMENTOS}

À FAPEMIG pelo financiamento do projeto e pela bolsa de pesquisa ao primeiro autor.

\section{REFERÊNCIAS}

1. Barnett, H.C.; Hunter, B.B. Illustrated genera of imperfect fungi. 3 ed. Minneapolis: Burgess Publications, p. 218, 1987.

2. Bewley, J.D.; Black, M. Seed: physiology of development and germination. 2nd ed. New York: Plenum Press, 1994. 445p.

3. Bezerra, A.K.D.; Bruno, R.A.; Ferrari, C.S.; Silva, G.Z.; Braga Junior, J.M.; Alves, E.U. Utilização de fungicidas no tratamento de sementes de mamona. In: Congresso Brasileiro de Mamona, 4.; Simpósio Internacional de Oleaginosas Energéticas, 1., João Pessoas. Anais. João Pessoa. Inclusão social e energia: anais. Campina Grande: Embrapa Algodão, 2010. p. 2180-2185.

4. Braccini, A.L.; Braccini, M.C.L.; Scapim, C.A. Mecanismos de deterioração das sementes: Aspectos bioquímicos e fisiológicos. Informativo ABRATES, Londrina, v.11, n.1, p.10-15, 2001.

5. Brasil. Ministério da Agricultura, Pecuária e Abastecimento. Regras para análise de sementes. Brasília, DF: Secretaria de Defesa Agropecuária, 2009. 399p.

6. Carvalho, N.M.; Nakagawa, J. Sementes: ciência, tecnologia e produção. 4.ed. Jaboticabal: Funep, 2000. 588p.

7. Chalfoun, S.M.; Pereira, M.C.; Resende, M.L.V.; Angélico, C.L.; Silva, R.A. Effect of powdered spice treatments on mycelial growth, sporulation and production of aflatoxin by toxigenic fungi. Ciência e Agrotecnologia, Lavras, v.28, n.4, p.856-862, 2004. Disponível em: <http://dx.doi.org/10.1590/ S1413-70542004000400018>. Acesso em: 20 de jul. 2017.

8. Chao, S.C.; Young, D.G. Screening for inhibitory activity of essential oils on selected bacteria, fungi and viruses. Journal Essential Oil Research, [S.I.], v.12, p.630-649, 2000. Disponível em: <http://dx.doi.org/10.1080/1 0412905.2000.9712177>. Acesso em: 20 de jul. 2017.

9. Coutinho, W.M.; Almeida, R.P.; Dantas, F.V.; Soares, D.J.; Araújo, A.E.; Milani, M. Eficácia de mistura de fungicidas químicos na microbiota e na qualidade fisiológica de sementes de mamoneira. Embrapa Algodão, 2012. 22 p. Boletim de Pesquisa \& Desenvolvimento, 91. Disponível em: https:// www.infoteca.cnptia.embrapa.br/bitstream/doc/926193/1/BOLPES91.pdf Acesso em: 20 de jul. 2017.

10. David, A.M.S.S.; Araujo, E.F.; Araujo, R.F.; Mizobutsi, E.H.; Amaro, H.T.R.; Reis, S.T. Qualidade sanitária de sementes de mamona (cv. IAC-226). Comunicata Scientiae, Bom Jesus, v.5, n.3, p.311-317, 2014.

11. Kobori, N.N. Tratamento fungicida e qualidade de sementes de mamona. 2011. 101p. Dissertação (Mestrado)-Escola Superior de Agricultura Luiz de Queiroz, Universidade de São Paulo, Piracicaba. Disponível em: $<$ http:// www.teses.usp.br/teses/disponiveis/11/11136/tde-02052011-085132/pt-br. php>. Acesso em: 20 de jul. 2017.

12. Machado, J.C. Tratamento de sementes no controle de doenças. Lavras: LAPS/UFLA/FAEPE, 2000. $138 \mathrm{p}$.

13. Maguire, J.D. Speed of germination-aid selection and evaluation for seedling emergence and vigor. Crop Science, Madison, n.2, p.176-177, 1962.

14. Marcos Filho, J. Teste de envelhecimento acelerado. In: Krzyzanowski, 
F.C; Vieira, R.D; França Neto, J.B. (Ed.). Vigor de sementes: conceitos e testes. Abrates, 1999. p.1-24.

15. Marcos Filho, J. Deterioração de sementes. In: Marcos Filho, J. (Ed.). Fisiologia de sementes de plantas cultivadas. Piracicaba: FEALQ, 2005. p.291-348.

16. Mariotto, P.R.; Barros, B.C.; Sugimori, M.H.; Menten, J.O.M.; Moraes, S.A.; Savy Filho, A. Efeito do tratamento químico de sementes de mamona (Ricinus communis L.) avaliado por diferentes métodos de patologia de sementes. Arquivos do Instituto Biológico, São Paulo, v.54, n.1/4, p.37-44, 1987.

17. Marroni, I.V.; Moura, A.B.; Ueno, B. Chemical and biological treatments of castor bean seeds: effects on germination, emergence and associated microorganisms. Revista Brasileira de Sementes, Londrina, v.34, n.1, p.21-28. 2012. Disponível em: <http://dx.doi.org/10.1590/S0101$31222012000100003>$. Acesso em: 20 de jul. 2017.

18. Santos Neto, A.L.; Carvalho, M.L.M.; Bárbara, C.N.V.; Alves, R.A.; Oliveira, A.S.; Oliveira, K.C. Qualidade fisiológica e sanitária de sementes de mamona tratadas com fungicidas. In: Congresso Brasileiro de Mamona, 3. 2008. Salvador. Anais. Salvador: Embrapa, 2008. 1 CD-ROM.
19. Ribeiro, M.F.; Araújo, E.F.; Souza, G.A.; Pires, R.M.A.; Araújo, R.F.; Martinez, P.A.H. Ribeiro, M.R.F. Coffee seeds conservation in natural environment with alternative fungi control. International Journal of Current Research, Índia, v.7, n.11, p.23091-23098, 2015. Disponível em: <http://www.journalcra.com/article/coffee-seeds-conservationnatural-environment-alternative-fungi-control $>$. Acesso em: 20 de jul. 2017.

20. Tropaldi, L.; Camargo, J.A.; Smarsi, R.C.; Kulezynski, S.M.; Mendonça, C.G.; Barbosa, M.M.M. Qualidade fisiológica e sanitária de sementes de mamona submetidas a diferentes tratamentos químicos. Pesquisa Agropecuária Tropical, Goiânia, v.40, n.1, p.89-95, 2010. Disponível em: <https:// www.revistas.ufg.br/pat/article/view/5586>. Acesso em: 20 de jul. 2017.

21. Villela, F.A.; Peres, W.B. Coleta, beneficiamento e armazenamento. In: Ferreira, A.G.; Borghetti, F. Germinação: do básico ao aplicado. Porto Alegre: Artmed, 2004. p.265-281.

22. Zonta, J.B.; Araujo, E.F.; Araujo, R.F.; Zonta, J.H.; Dias, L.A.S.; Ribeiro, P. H. Armazenamento de sementes de pinhão manso em diferentes embalagens e ambientes. Bioscience Journal, Uberlândia, v.30, n.2, p.599-608, 2014. Disponível em: <http://dx.doi.org/10.1590/S0101-31222012000400015>. Acesso em: 20 de jul. 2017. 